Landscapes of Memory 


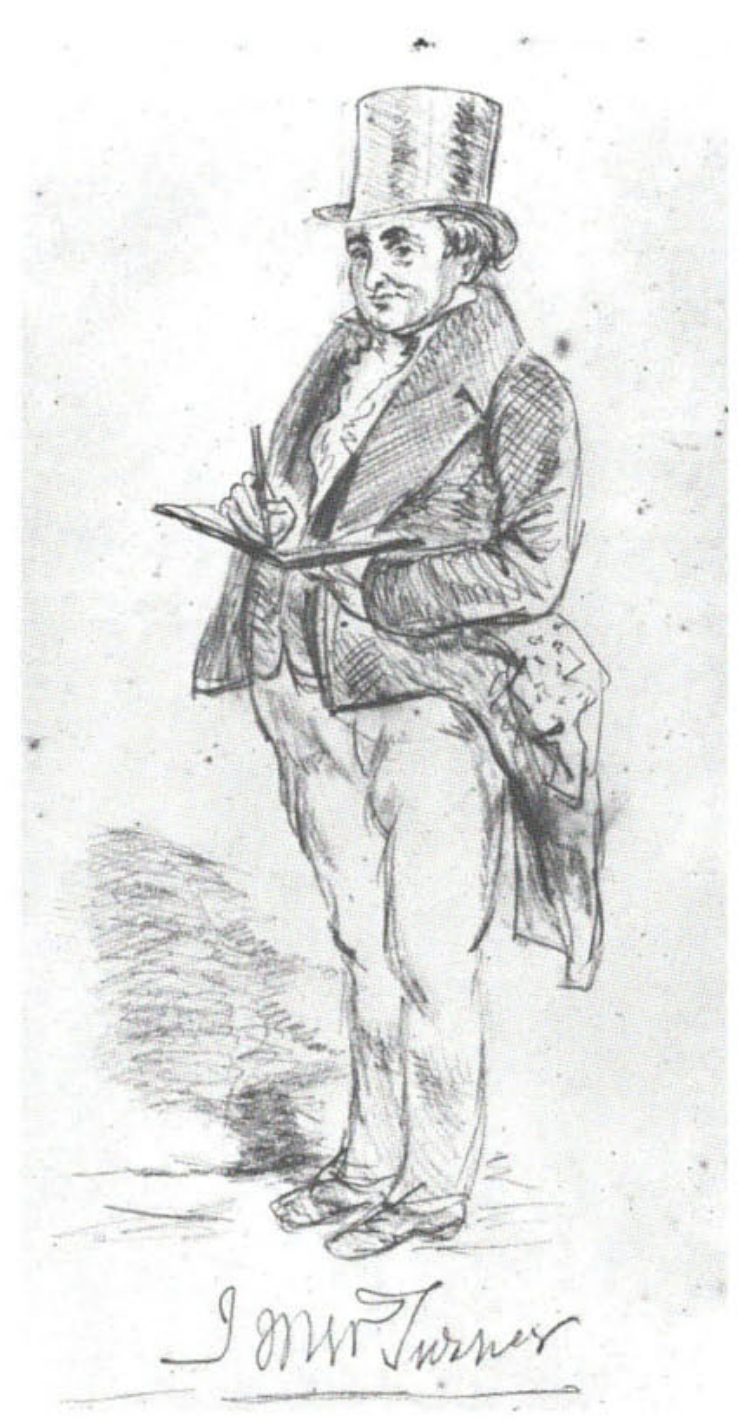




\section{Landscapes of Memory}

\section{Turner as Illustrator to Scott}

Gerald Finley

University of California Press Berkeley and Los Angeles 
University of California Press

Berkeley and Los Angeles

Copyright 0 Gerald Finley, 1980

Library of Congress Catalog Card Number : 80-5956

I S B N : o-520-04436-3

Designed by Ray Carpenter

Printed in Great Britain by The Scolar Press

Ilkley, West Yorkshire

London. 